\title{
Erratum: Interleukin 31, a cytokine produced by activated T cells, induces dermatitis in mice
}

Stacey R Dillon, Cindy Sprecher, Angela Hammond, Janine Bilsborough, Maryland Rosenfeld-Franklin, Scott R Presnell, Harald S Haugen, Mark Maurer, Brandon Harder, Janet Johnston, Susan Bort, Sherri Mudri, Joseph L Kuijper, Tom Bukowski, Pamela Shea, Dennis L Dong, Maria Dasovich, Francis J Grant, Luann Lockwood, Steven D Levin, Cosette LeCiel, Kim Waggie, Heather Day, Stavros Topouzis, Janet Kramer, Rolf Kuestner, Zhi Chen, Don Foster, Julia Parrish-Novak \& Jane A Gross

Nature Immunology 5, 752-760 (2004).

The published version of this article failed to include the microarray accession numbers. They are listed here: Geo microarray accession numbers. GSE1304, Control and Il31 tx NHEK cells; GSM21603, NHEK control; GSM21604, NHEK Il-31 tx. Nature Immunology regrets this error.

\section{Corrigendum: The ubiquitin-modifying enzyme A20 is required for} termination of Toll-like receptor responses

David L Boone, Emre E Turer, Eric G Lee, Regina-Celeste Ahmad, Matthew T Wheeler, Colleen Tsui, Paula Hurley, Marcia Chien, Sophia Chai, Osamu Hitotsumatsu, Elizabeth McNally, Cecile Pickart \& Averil Ma Nature Immunology 5, 1052-1060 (2004).

In the published article, Figure 1a was incorrect. The correct figure is printed here.

a

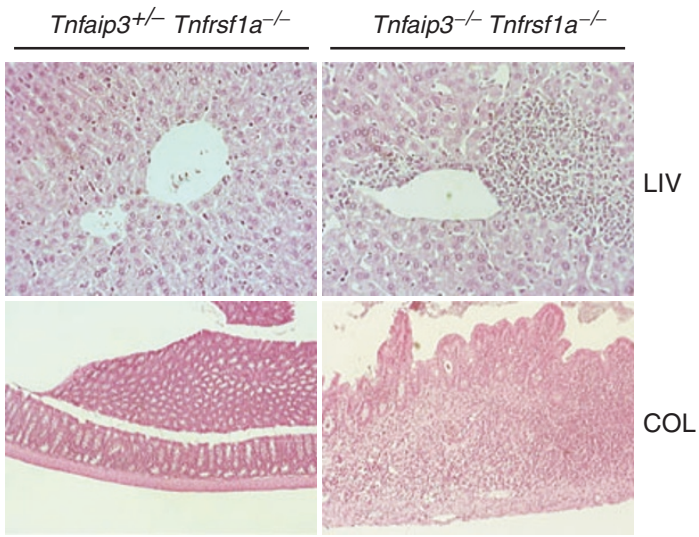

